\title{
Contextualizando para aprender: contribuição da história da matemática no ensino fundamental
}

Falconiere Leone Bezerra de Oliveira ${ }^{1}$

Ciron de Oliveira Moura ${ }^{2}$

\section{Resumo}

O presente texto aborda a experiência, provinda de um curso de extensão, do uso da História da Matemática em uma turma de $6^{\mathrm{a}}$ ano de uma escola pública de Ensino Fundamental no interior do Rio Grande do Norte. A experiência foi fruto de conhecimentos pedagógicos adquiridos no curso de extensão, "Ensino de Matemática x História da Matemática" desenvolvido pela Universidade Potiguar. A ação prática foi dividida em seis encontros sistemáticos que organizasse uma melhor compreensão dos alunos sobre a matemática. O uso da História da Matemática como suporte pedagógico ajuda a compreender a matemática como criação humana que auxilia na construção do sujeito ativo, reflexivos e críticos, assim como ajuda os sujeitos a se perceberem como parte de um todo maior dentro da sociedade, usamos como metodologia para a inserção da História da Matemática os Três Momentos Pedagógicos em sala de aula. Dessa forma, ampliar os horizontes, as possibilidades e as estratégias de ensino de matemática é uma função essencial dos professores do ensino fundamental e educadores matemáticos que durante muito tempo buscam humanizar a disciplina dentro do contexto atual da sociedade.

Palavras-chave: Ensino de Matemática, História da Matemática, Práticas de Ensino.

\begin{abstract}
The present text approaches the experience, from an extension course, of the use of the History of Mathematics in a class of 6th year of a public elementary school in the interior of Rio Grande do Norte. The experience was the result of pedagogical knowledge acquired in the extension course, "Teaching of Mathematics x History of Mathematics" developed by Potiguar University. The practical action was divided into six systematic meetings that organized a better understanding of the students about mathematics. The use of the History of Mathematics as a pedagogical support helps to understand mathematics as a human creation that assists in the construction of the active subject, reflective and critical, as well as helps the subjects to perceive themselves as part of a larger whole within the society, we use as methodology For the insertion of the History of Mathematics the Three Pedagogical Moments in the classroom. Thus, broadening horizons, possibilities and strategies for teaching mathematics is an essential function of elementary school teachers and mathematical educators who have long sought to humanize the discipline within the current context of society.
\end{abstract}

\footnotetext{
1 falconiereleone@gmail.com

2 cironmoura74@gmail.com
} 
Keywords: Teaching of Mathematics, History of Mathematics, Teaching Practices. INTRODUÇÃO

Historicamente o entendimento sobre o ensino de matemática vem se modificando e diante disso, existindo, diversas formas de se compreender o ensino e a aprendizagem de matemática. Tudo isso, devido os diferentes contextos socioculturais na qual a sociedade está inserida.

A matemática é hoje fruto de uma construção histórica, cultural e social, ou como podemos dizer, fruto de uma construção contextualizada que envolve esses elementos (históricos, culturais e sociais), ganhando grande acuidade no desenvolvimento das sociedades. Contraditoriamente, a sua importância discrepa da necessidade de buscar novas formas de ensiná-la impetrando-a na sociedade e na escola.

A partir do entendimento da importância da História da Matemática, decorrente do curso de extensão "Matemática x História da Matemática", para o ensino da matemática nos anos iniciais, foi pensada uma intervenção escolar. Usamos como subsídio para a intervenção em sala de aula a História da Matemática, mas especificamente a história dos números, com o objetivo de potencializar o processo de ensino-aprendizagem.

O presente artigo trata-se de um relato de experiência, positiva, do uso da História da Matemática em uma turma de $6^{a}$ anos do ensino fundamental na cidade de Santa Cruz/RN para a qual a esses elementos contribuíram para uma melhor aprendizagem do ensino de fração.

\section{Contexto do Ensino da Matemática}

Todo conhecimento é contextual, inclusive o matemático, que envolve elementos construídos historicamente pela humanidade que é conquistado em processo contínuo e cumulativo. O implicante é que contextualmente o conhecimento matemático foi elaborado por partes ao longo do tempo.

Dentro do nosso âmbito, falamos aqui das discussões no Brasil entorno do Ensino da Matemática, dando uma ênfase à década de 1950, Período marcado por inúmeras discussões entorno do Ensino da Matemática. Para Ubiratan D’Ambrósio (2001) essas discussões eram influenciadas por tensões internacionais nas quais procuravam novos meios para uma matemática mais humana.

Salamunes (2010) corrobora apontando que essas tensões foram impulsionadas pela expansão da indústria e pela necessidade de reconstrução social e econômica do período pós- 
guerra. D'Ambrósio (2001) contribui com a ideia de que a matemática, nesse período, era um instrumento de reconstrução socioeconômica.

Instrumentos materiais (armamento e tecnológico de suporte) e intelectuais (ideologias e teorias sociais e econômicas) foram desenvolvidos como suporte ao conflito. Esses instrumentos materiais e intelectuais tinham e tem, como base, a matemática. Para o desenvolvimento desses instrumentos surgiram, como aconteceu em outros tempos históricos, novas áreas de pesquisa matemática. Não só nos conteúdos, mas também novos conceitos de rigor e de critérios de verdade (D’AMBRÓSIO, 2001, p. 16).

A matemática dentro desse contexto pós-guerra passou por um processo de reconstrução de suas formas e métodos, influenciando diretamente o modo de se ensinar nas escolas, pois as percepções técnicas e científicas do seu uso se tornava mais presente nas escolas, diante desse contexto de ideários.

Sobre o ensino nesse período, as escolas brasileiras tinham como foco o ensino tradicional da matemática, o que causava insatisfação entre os professores e estudiosos diante da forma que se vinha desenvolvendo nas escolas. Dessa forma, a relação estabelecida no Ensino de Matemática na década de 1950 fica evidente, dois papeis distintos, o do professor e do aluno, no qual o professor detentor do saber e o aluno sujeito passivo deste.

Este ensino acentua a transmissão do saber já construído, estruturado pelo professor, a aprendizagem é vista como impressão, na mente dos alunos, das informações apresentadas nas aulas. O trabalho didático escolhe um trajeto "simples" - transferir para o aprendiz os elementos extraídos do saber criado e sistematizados, ao longo da história das ciências, fruto do trabalho dos pesquisadores. Aulas consistem, sobretudo, em explanação sobre o tema dos programas; entende-se que basta o professor dominar a matéria que leciona para ensinar bem (MICOTTO, 1999, p. 156-157).

Dentro desse contexto Paulo Freire (2005) aponta que o professor passa a desempenhar um papel de opressor impondo-se como único detentor de conhecimento, nesse caso da matemática. Pois o aluno como sujeito passivo que apenas precisa aprender os conteúdos não mantendo nenhum nexo, dos conteúdos, com a vida cotidiana, conteúdos apenas academicistas.

Castro, Carvalho e Pérez (2001) em consonância com o que foi exposto apontam que o ensino tradicional da matemática priorizava a memorização pela memorização, ou seja, a repetição mecânica e exaustiva de exercício e modelos. Dessa forma, as práticas de ensino tradicional da matemática promove a passividade em suas atitudes, ou seja, a simples aceitação frente a situações que se apresentam em diversos contextos sociais.

Diante da insatisfação quanto ao Ensino da Matemática no Brasil e da mobilização de professores e educadores matemáticos, foi desencadeado vários encontros e congressos que proveram o Movimento da Matemática Moderna no Brasil. 
A matemática moderna nasceu como um movimento educacional inscrito numa politica de modernização econômica e foi posta na linha de frente do ensino por se considerar que, juntamente com a área das Ciências, ela constituía uma via de acesso privilegiado para o pensamento científico e tecnológico. Para tanto procurou-se aproximar a matemática desenvolvida na escola da matemática como é vista pelos estudiosos e pesquisadores.

$\mathrm{O}$ ensino proposto fundamentava-se em grandes estruturas que organizam o conhecimento matemático contemporâneo e enfatizava a teoria dos conjuntos, as estruturas algébricas, a topologia, etc. esse movimento provocou em vários países do mundo inclusivo no Brasil, discussões e amplas reformas no currículo de matemática (BRASIL, 1998, p. 19).

Fiorentini (1995) exclama que o Movimento da Matemática Moderna (MMM), portanto, buscou reformular, reorganizar e modernizar os currículos das escolas, buscando estreitar a matemática escolar da matemática pura. Com esse estreitamento, o ensino da matemática passou a dar ênfase às estruturas que compõem os conhecimentos da disciplina, dando destaque excessivo para a lógica, álgebra, teoria dos conjuntos, etc.

No entanto, esse Movimento deixa de lado os processos que os produzem, por que, nesse movimento, a ênfase é dada ao lógico em detrimento do psicológico, o formal sobre o social, o sistemático-estrutural sobre o histórico (BRASIL, 1998). A matemática dentro do Movimento foi tratada como neutra pronta e acabada e como se ela não tivesse nenhuma relação com o contexto social, cultural e político de cada época (FIORENTINI, 1995).

Com uma estrutura rígida centrada no academicismo, os alunos passam a apresentar dificuldades na aprendizagem, não conseguindo estabelecer vínculos entre o que era ensinado e a realidade vivida (FIORENTINI, 1995; MICOTTO, 1999; D’AMBRÓSIO, 2001).

Para D’Ambrósio (2001) esse Movimento, não ponderou aspectos importantíssimos como linguagem e simbologias, ajustadas as crianças e suas diferentes faixas etárias. "Essa reforma deixa de considerar um ponto básico que viria a torna-se seu maior problema: o que se propunha estava fora do alcance dos alunos, em especial daqueles das séries iniciais do Ensino Fundamental” (BRASIL, 1998, p. 19).

O Movimento da Matemática Moderna passa a entrar em decadência no final da década de 1970, deixando, segundo D’Ambrósio (2001) um saldo positivo, pois ele favorece novas formas de conduzir o ensino da matemática em sala de aula, buscando ampliar os debates e discussões entorno do processo de ensino e aprendizagem da matemática. Esse movimento diminuiu a ênfase em contas e correções e cálculos envolvendo muita "decoreba", favorecendo uma participação maior dos alunos e de novas formas de se pensar as práticas pedagógicas para o ensino da matemática. 
Considerando a matemática como ciência em construção contextual, Segundo Fiorentini (1995), relacionando a aspectos sociais e históricos, foi a partir da década de 1980 que a etnomatemática e o ensino da matemática a partir de problemas, passa a ganhar espaços nas discussões sobre as práticas de ensino de matemática:

A matemática, sob o ponto de vista histórico-crítico não pode ser concebido
como um saber pronto e acabado, mas, ao contrário, como um saber vivo,
dinâmico e que historicamente, vem sendo construído, atendendo a estímulo
externo (necessidades sociais) e internos (necessidades teóricas de ampliação
dos conceitos) (FIORENTINI, 1995, p. 31).

Essas necessidades são pautadas na ideia que a matemática não deve ser fragmentada do contexto social dos alunos, pode ser contextual, pois é um saber vivo e dinâmico encontrada em todos os âmbitos da sociedade, respondendo aos insights sociais.

Essa concepção de ensino de matemática relaciona a importância de se articular o contexto/ realidade, com a construção do conhecimento matemático. Podemos dizer que essa atividade, matemática, na escola não se resume a resoluções de problemas prontos e fechados (FREIRE, 2005), mas, sim como uma construção constante, no qual os alunos se apropriam de conhecimento que servirá para compreender a realidade e poder, de forma coletiva, transformála (DELIZOICOV; ANGOTTI; PERNAMBUCO, 2009).

É nesse universo que a História da Matemática passa a marcar o ambiente no âmbito educacional, como estratégia metodológica para compreender a matemática como algo cultural, social, histórico e econômico, ou seja, contextual, na qual coloca o aluno com sujeito ativo do conhecimento.

\section{CONTEXTO DA HISTÓRIA DA MATEMÁTICA}

A contribuição da História e da História da Matemática para a Educação e o Ensino da Matemática vem ganhando cada vez mais espaço entre os educadores, em geral e principalmente entre os educadores matemáticos no Brasil, especialmente quando se trata da contribuição dessa estratégia metodológica no processo de ensino-aprendizagem em todos os níveis e modalidades de ensino.

O uso dessa estratégia, História da Matemática, como recurso didático associado a outros recursos que promovam uma melhor compreensão do ensino e aprendizagem dos alunos se torna essencial quando nos permitimos contextualizar e inserir os alunos dentro de um contexto mais amplo que a própria sala de aula, livros e professores, o contexto histórico (MENDES; FARIAS, 2015).

A história é considerada como uma ferramenta que procura auxiliar os professores no ensino e na aprendizagem em Matemática, pois contém 
argumentos importantes sobre como os alunos aprendem e adquirem esse conhecimento, a medida em que se observam a construção da matemática ao longo da história (OLIVEIRA; ROSA;VIANA, 2014, 109).

A História da Matemática, quando usada de forma coerente com os níveis de ensinos, passa a desempenhar, em situações de ensino, um importante recurso que favorece o despertar crítico dos sujeitos, principalmente se for empregado na educação básica, mais especificamente no Ensino Fundamental.

O que se apresenta diante de vários estudos (SANTOS, 2016; D’AMBRÓSIO, 2001; FIORENTINNI, 1995) são ações efetivas voltadas para um uso da História da Matemática pelos professores dos primeiros anos do Ensino Fundamental são escassas. Esse recurso, apesar de sua escassez, nos primeiros anos do Ensino Fundamental, é extremamente importante, pois ele busca dá uma ressignificação ao conhecimento matemático produzido ao longo do tempo pela sociedade (MENDES, 2009).

Diante disso, Miguel e Miorim (2011) apresentam alguns preceitos a esse recurso:

(1) A matemática como uma criação humana; (2) as razões pelas quais as pessoas fazem matemática; (3) as necessidades práticas, sociais, econômicas e físicas que servem de estímulo ao desenvolvimento das ideias matemáticas; (4) as conexões existentes entre matemática e filosofia, matemática e religião, matemática e lógica, etc.; (5) a curiosidade estritamente intelectual que pode levar à generalização e extensão de ideias e teorias; (6) as percepções que os matemáticos têm do próprio objeto da matemática, as quais mudam e se desenvolvem ao longo do tempo; (7) a natureza de uma estrutura, de uma axiomatização e de uma prova (MIGUEL; MIORIM, 2011, p. 53).

A partir dos preceitos apontados, podemos dizer que o uso da História da Matemática, como recurso didático, possibilita a crença que essa ciência é descontextualizada e que apenas contribui para uma alienação do ensino, mas sim que faz parte de um contexto humano que promove um saber sistemático e crítico.

Ainda justificando a importância desse recurso em sala de aula, que serve como ponto de partida para problematização pedagógica, Miguel e Miorim (2011):

Uma história pedagogicamente vetorizada não é nem uma história adocicada ou suavizada, nem uma história distorcida, nem uma adaptação ou transposição didática das "verdadeiras" histórias da Matemática para o âmbito da escola [...] Uma História da Matemática pedagógicamente vetorizada poderia prestar grande auxílio aos professores intencionados em se contrapor a tal tendência tecnicista e aparentemente neutra do ensino. (2005, p.157-159).

Essa contribuição pedagogicamente vetorizada motiva os alunos a querer se “embrenhar" com a disciplina despertando o processo de humanização da própria ciência no decorrer para "o aprender" dos alunos retirando grande fardo da tendência técnica e aparentemente neutra do ensino, deixando-a mais leve. 
O que podemos diante do que Miguel e Miorim (2011) abordam que o conhecimento histórico acomoda aos alunos o despertar crítico e investigativos. Dessa forma, a história pode colaborar com as reflexões que os alunos possam ter sobre várias barreiras e soluções de problemas matemáticos do seu cotidiano (MIGUEL et al , 2009; D’AMBRÓSIO, 2001).

Então, o uso da História da Matemática busca para o Ensino da Matemática o máximo de esclarecimento possível sobre determinados assuntos matemáticos, com o objetivo de explorar implicações pedagógicas nas atividades em sala de aula (MIGUEL ET AL, 2009; D’AMBRÓSIL, 2001).

Nesse sentido Ubiratan D’Ambrósio (1996) colabora sobre ensino da matemática como instrumento contextual da seguinte forma:

1. Para situar a matemática como uma manifestação cultural de todos os povos em todos os tempos, como a linguagem, os costumes, os valores, as crenças e os hábitos, e como tal diversificada nas suas origens e na sua evolução; 2. Para mostrar que a matemática que se estuda nas escolas é uma das muitas formas de matemática desenvolvidas pela humanidade; 3. Para destacar que essa matemática teve sua origem nas culturas da Antiguidade mediterrânea e se desenvolveu ao longo da Idade Média e somente a partir do século XVII se organizou como um corpo de conhecimentos, com um estilo próprio; 4.E desde então foi incorporada aos sistemas escolares das nações colonizadas e se tornou indispensável em todo o mundo em consequência do desenvolvimento científico, tecnológico e econômico. (D’AMBROSIO, 1996, p. 10).

Nesse contexto, a história da matemática equilibra uma ideia de que os conhecimentos matemáticos fazem parte de um ente social, ou seja, surgindo de manifestações culturais de diversos povos ao longo da história da humanidade.

\section{Desenvolvimento da Experiência}

Seguindo a tendência, do uso da História da Matemática como recurso metodológico em sala de aula, adequando-os aos conteúdos pertinentes ao sexto ano do Ensino Fundamental, em escola pública municipal no interior do Rio Grande do Norte. A experiência foi dividia em três momentos (que durou uma semana) significativos desenvolvidos por Delizoicov, Angotti e Pernambuco (2009): Estudo da Realidade, Organização do Conhecimento e Aplicação do Conhecimento.

A utilização do uso da História da Matemática em uma turma do Ensino Fundamental surgiu de um curso de extensão que fizemos parte "Educação Matemática $x$ História da Matemática", nesse curso foi apontado à importância de se utilizar a História da Matemática 
como suporte pedagógico para um melhor desenvolvimento do ensino e da aprendizagem da matemática nas diversas etapas de ensino.

O uso do referencial teórico-metodológico dos Três Momentos Pedagógicos (Estudo da Realidade, Organização do Conhecimento e Aplicação do Conhecimento) para o desenvolvimento da experiência foi assumido com uma possibilidade de contextualizar os conhecimentos históricos da Matemática e torná-los significativos.

A elaboração da nossa experiência, como dito anteriormente, foi dividida em três momentos concêntricos. Para não perdemos a dialeticidade do processo, tentamos em cada etapa mostrar didaticamente como a nossa experiência obteve um salto qualitativo no processo de ensino-aprendizagem.

Em um primeiro momento, buscamos encontrar as fragilidades no que concerne a matemática com os alunos. Dessa forma, fizemos um estudo real, ou seja, procuramos a partir do Estudo da Realidade, momento que se cria a necessidade de compreender uma situação da realidade local, problematizando-a.

Buscamos a partir de operações matemáticas simples (adição, subtração, multiplicação e divisão) contextualizadas a partir do cotidiano dos alunos, o que eles sabiam. Foi nesse momento que colocamos a realidade, matemática, apresentada ao aluno codificado, necessitando ser descodificada, por meio de aquisições de outras visões. Nessa etapa, compreendemos as lacunas epistemológicas que os alunos tinham e buscamos sistematizá-las para o planejamento.

Segundo momento, tão importante quanto o primeiro, Organização do Conhecimento, que é basicamente o estudo de partes do conhecimento universalmente construído, o conteúdo escolar renovado, sempre sobre forma de problematização e cotejamento das visões distintas, porém sem deixar de dar prioridade ao conhecimento já acumulado (DELIZOICOV; ANGOOTTI; PERNAMBUCO, 2009). É nesse momento que procuramos inserir dentro do planejamento dos professores o conteúdo da História da Matemática ligado aos conteúdos préestabelecidos, buscando contextualizar a História da Matemática como forma de despertar o senso crítico.

A Aplicação do Conhecimento requer uma dinâmica que evolva a dialética dos conhecimentos iniciais para o fim desejável. Pois os conteúdos apreendidos, na primeira etapa, são extrapolados para novas situações, são usados para reinterpretar os primeiros. É nesta etapa, de nossa experiência que dinamizamos de forma mais didática.

Então, esse momento foi desenvolvido da seguinte forma: organizamos em um grande ciclo, e questionamos de onde surgem os números? Qual a importância dos sinais numéricos? 
Dentro desses dois questionamentos houve um verdadeiro alvoroço, pois simplesmente eles não tinham a menor ideia de como responder, inicialmente, esses questionamentos. Depois de certa excitação da turma, começamos a contar uma pequena história, sobre o qual passeamos no universo da civilização Maia, ao passearmos por essa civilização prendemos a atenção contando um pouco sobre as primeiras formas de contagem, dessa forma, "o intuito de trabalhar as propriedades envolvidas neste sistema de numeração e que possam, posteriormente, ser comparadas com o sistema de numeração indo-arábico" (SILVIA; TRIVIZOLI, 2016, p. 10). Assim como apresentamos algumas forma de contagem, elaborada pela civilização.

Após esse trabalho envolvendo História da Matemática, pedimos aos alunos que se dividisse em quartetos, cada quarteto foi pesquisar na biblioteca um pouco sobre as civilizações antigas e suas formas de comércio, sociedade e modo de vida. Após a pesquisa, pedimos para eles representarem a forma que essas civilizações comercializavam suas mercadorias. Para isso, disponibilizamos alguns objetos simples e de alcance, como copos plásticos, grãos de feijão, dados, etc. para que eles possam fazer o agrupamento de valores das unidades.

No último momento da Aplicação do Conhecimento teve inicio um diálogo com os alunos sobre as diferentes características dos sistemas numéricos e como de forma simples, sugiram sugestões e contextualizações que podem melhorar os raciocínios dos alunos nas operações matemáticas. Por último, todas as atividades foram registradas em um diário para que possamos avaliar os alunos com cautela, de forma qualitativa, levando em consideração os conhecimentos primários sobre a matemática e o que conseguimos alcançar em um curto intervalo de tempo.

Toda a dinâmica dos Três Momentos Pedagógicos foi dividida em um bloco de aulas que durou uma semana, na qual pudessem ter espaço para que esses momentos, concêntricos, pudessem dar respaldo ao salto qualitativo que se esperava, sobre História da Matemática e sua contribuição para o ensino.

\section{CONSIDERAÇÕES}

Através das reflexões sobre abordagem do uso dos Três Momentos Pedagógicos no processo de contextualização da História da Matemática, os resultados foram inúmeros, quando admitimos também o processo de construção da formação humana da matemática e dos alunos. A partir da abordagem histórica e principalmente referencial teórico-metodológico adotado para a compreensão da importância desse recurso didático (História da Matemática) emergiram diversas questões que orientaram todo o trabalho no decorrer de uma semana. 
No contexto da experiência ficou reforçado, que trabalhar com esse recurso didático associado a um referencial teórico-metodológico coerente deixa exposto e perceptível que a História da Matemática contribui significativamente para o desenvolvimento crítico dos alunos.

Outra orientação encontrada durante o desenvolvimento do trabalho, que uma proposta de trabalho pautada nesse recurso teórico-metodológico e didático, pode contribuir para uma construção de escola emancipadora que resiste e enfrenta modelos hegemônicos excludentes.

Igualmente importe, é a constatação de que, as orientações tomadas neste trabalho a partir dos Três Momentos Pedagógicos e a História da Matemática, nos permitem também discutir o currículo de matemática, a avaliação escolar e instrumentos avaliativos para/na matemática de forma dialética problematizadora que os Três Momentos Pedagógicos permitem.

Diante disso, a experiência, frutífera, teve um salto qualitativo na disciplina de matemática, quando olhamos o conjunto de situações proposta aos alunos para que os mesmo possam compreender melhor a matemática e também perceber que a mesma faz parte do seu cotidiano. Pois o envolvimento dos alunos para compreender melhor os aspectos históricos da matemática deu o incentivo que eles precisavam para passarem a olharem as disciplinas com "outros olhos".

Dessa forma, a compreensão da matemática com algo contextual que envolve a cultura e a sociedade é de suma importância, pois é evidente a necessidade em utilizar esse recurso didático, História da Matemática, nos primeiros anos do ensino fundamental para um melhor desenvolvimento da matemática na sociedade, na prática educativa e na escola.

\section{Referências}

BRASIL, Secretaria de Educação Básica. Parâmetros Curriculares Nacionais. Matemática. Brasília: MEC; SEB, 1998.

CASTROS, Amélia Domingues; CARVAlHO, Anna Maria Pessoa; PÉREZ, Daniel Gil. Ensinar a Ensinar: didática para escola fundamental e médio. São Paulo: Thomson Learning, 2001.

DELIZOICOV, Demétrius; ANGOTTI, José André; PERNAMBUCO, Marta Maria Castanho Almeida. Ciências: Fundamentos e Métodos. São Paulo: Cortez, 2009.

FIORENTINI, Dário. Alguns Modos de Ver e Conceber o Ensino da Matemática no Brasil. Zetetike (UNICAMP), Campinas, SP, v. 3, n.2, p. 1-36, 1995.

D’AMBRÓSIO, Ubiratan. Etnomatemática: Ele entre as tradições e a modernidade. 1. ed. Belo Horizonte: Autêntica Editora, 2001. 
D’AMBrosio, Ubiratan. História da Matemática e Educação. Caderno Cedes 40 História e Educação Matemática. 1 ed. Campinas: Papirus, 1996

MENDES, Iran Abreu. Matemática e investigação em sala de aula: tecendo redes cognitivas na aprendizagem. São Paulo: Editora Livraria da Física, 2009.

MENDES, Iran Abreu.; Farias, C. A. . HISTÓRIA DA EDUCAÇÃO MATEMÁTICA BRASILEIRA: entre genealogias e coletivos de pensamento. HISTEMAT: Revista de História da educação Matemática, v. 01, p. 89-103, 2015.

MIGUEL, Antonio; MIORIM, Maria Ângela. História da Matemática: uma prática social de investigação em construção. Educação em Revista, Belo Horizonte, n. 36, dez. 2002.

MIGUEL, Antonio et al. História da Matemática em atividades didáticas. 2. ed. São Paulo: Editora Livraria da Física, 2009.

MICOTTI, M. C. de O. O ensino e as propostas pedagógicas in: BICUDO, Maria A. Viggiani. (Org.) Pesquisa em educação matemática: Concepções e perspectivas. São Paulo, Editora IJNESP, 1999.

OLIVEIRA, Davidson Paulo Azevedo; ROSA, Milton; VIANA, Marger da Conceição. Ventura. A Perspectiva Sociocultural da História da Matemática na Sala de Aula: Possibilidades e Limites.. REMATEC. Revista de Matemática, Ensino e Cultura (UFRN), v. 9, p. 107129,2014

ROQUE, Ana Catarina Cantoni. Uma investigação sobre a participação da História da Matemática em uma sala de aula do ensino fundamental. 2012. 148 f. Dissertação (Mestrado) - Programa de Pós-graduação em Educação, Universidade Federal de Minas Gerais, 2012.

SANTOS, Anderson Oramísio. História da matemática como metodologia alternativa para o desenvolvimento da prática pedagógica nos primeiros anos do ensino fundamental. 2013. 175 f. Dissertação (Mestrado) - Programa de Pós-Graduação em Educação, Universidade Federal de Uberlândia, Uberlândia, 2013.

SILVA, Eliane Siviero; TRIVIZOLI, Luciele Maria . História da Matemática nos Anos Iniciais do Ensino Fundamental: uma proposta para o ensino de sistemas de numeração. In: XX EBRAPEM - Encontro Brasileiro de Estudantes de Pós-Graduação em Educação Matemática, 2016, Curitiba. 